\title{
Transição agroecológica em cooperativa de agricultores familiares de Itapuranga, Goiás
}

\section{Agroecological transition in a cooperative of family farmers in Itapuranga, Goias, Brazil}

\author{
Fernanda Pereira da Silva ${ }^{(1)}$; Guilherme Resende Oliveira ${ }^{\left(D^{2}\right.}$; Cleyzer Adrian da Cunha ${ }^{\left(D^{3}\right.}$; Alcido Elenor \\ Wander 1 (D)
}

\begin{abstract}
${ }^{1}$ Mestre em Desenvolvimento Regional, Centro Universitário Alves Faria (UNIALFA), Goiânia, Goiás, +556232725120, fesilvape@gmail.com. ${ }^{2}$ Doutor em Economia, Docente do Programa de Pós-Graduação em Desenvolvimento Regional, Centro Universitário Alves Faria (UNIALFA), Goiânia, Goiás, guilherme.oliveira@unialfa.com.br. ${ }^{3}$ Doutor em Economia Aplicada, Docente da Faculdade de Administração, Ciências Contábeis e Ciências Econômicas, Universidade Federal de Goiás, Goiânia, Goiás, cleyzercunha@gmail.com. ${ }^{4}$ Doutor em Ciências Agrárias (Concentração: Economia Agrícola), Docente do Programa de Pós-Graduação em Desenvolvimento Regional, Centro Universitário Alves Faria (UNIALFA), Goiânia, Goiás, alcido.wander@unialfa.com.br.
\end{abstract}

\begin{tabular}{l} 
A R T I G O \\
\hline Recebido: $24 / 03 / 2020$ \\
Aprovado: 20/06/2020 \\
\\
\hline Palavras-chave: \\
Agrossistemas sustentáveis \\
Cooperativismo \\
Processos agroecológicos
\end{tabular}

Key words:

Sustainable farming systems

Cooperativism

Agroecological processes

\section{R E S U M O}

O presente trabalho buscou descrever os avanços, benefícios e dificuldades da transição agroecológica do sistema de produção de frutas e hortaliças em cooperativa de agricultores familiares de Itapuranga, Goiás, Brasil, bem como os custos de implantação do cultivo convencional e agroecológico e a rentabilidade auferida com a prática agroecológica. Para a realização dessa pesquisa, utilizou-se o delineamento de uma abordagem de pesquisa qualitativa exploratória. Como instrumento de coleta de dados foram utilizados questionários estruturados e entrevistas não estruturadas. De acordo com os resultados é perceptível a satisfação dos que trabalham com as práticas agroecológicas, os que investiram em mão de obra, bem como em assistência técnica. Os agricultores que possuíam mais de 15 hectares de terras concordam que suas receitas aumentaram embora tivessem dificuldades para dar continuidade aos projetos devido à ausência do apoio técnico após sua finalização. Durante a execução, a assistência técnica foi apontada como um problema devido à alta rotatividade de pessoal. Por fim, o sucesso dos agricultores que fizeram a transição do sistema de produção convencional vis-à-vis agroecológico resultou, sobretudo, em maiores ganhos econômicos, em parte, provenientes do recebimento de insumos e assistência técnica da cooperativa. Os produtores que possuíam mais recursos financeiros, mão de obra qualificada, consciência social e ambiental foram os que conseguiram maior agregação de valor ao produto final.

\section{A B S T R A C T}

This study aimed to describe the advances, benefits, and difficulties of the agroecological transition of the fruit and vegetable production system in a cooperative of family farmers in Itapuranga, Goias, Brazil, as well as the costs of implementing conventional and agroecological cultivation and the profitability obtained. with agroecological practice. To carry out this research, we used the outline of a described approach that can be classified as exploratory qualitative research that used the case study to carry out the field research. As a data collection instrument, structured questionnaires and unstructured interviews were used. According to the results, the satisfaction of those who work with agroecological practices, those who invested in labor, as well as in technical assistance, is noticeable. Farmers who owned more than 15 hectares of land agree that their revenues have increased even though they have difficulties to continue the projects due to the lack of technical support after its completion. During execution, technical assistance was identified as a problem due to the high turnover of personnel. Finally, the success of farmers who transitioned from the conventional production system vis-à-vis agroecological resulted, mainly, in greater economic gains, partly from the receipt of inputs and technical assistance from the cooperative. Producers who had more financial resources, qualified labor, social and environmental awareness were those who achieved greater added value to the final product.

\author{
Revista Verde \\ ISSN 1981-8203 \\ Pombal, Paraíba, Brasil
}

v. 15, n.3, jul.-set., p.309-318, 2020 doi: $10.18378 /$ rvads.v15i3.7773 


\section{INTRODUÇÃO}

A agricultura brasileira a partir de meados da década de 1970 passou por processos de transformação da base tecnológica com a modernização do agronegócio e o crescimento do setor agrícola. Em virtude desse processo ocorreram algumas transformações sociais no ambiente rural tais como, a concentração da renda rural e o aumento das desigualdades e da exclusão no campo. Essa transformação social e econômica possibilitou aos agricultores um papel de destaque no ambiente rural brasileiro, visto que esse crescente fomento na produção agropecuária geram empregos rurais e urbanos (MATOS; PESSÔA, 2011).

Neste contexto, uma parte dos pequenos agricultores saiu prejudicada, haja vista que parcela da produção não alcançava preços justos ou alguns agricultores eram obrigados a entregar a safra para terceiros, a fim de pagar dívidas contraídas para fazer seu plantio. Desse modo, o pequeno agricultor não tinha meios econômicos para se desenvolver, ficando à mercê de políticas públicas que valorizassem o homem do campo e de incentivos para fomentar a pequena propriedade (BOLFE, 2018).

Assim sendo, tardiamente, a mudança de paradigma se deu somente em meados da década de 1990, com a expressão "agricultura familiar", que emergiu dos movimentos sociais do campo e da criação do PRONAF (Programa Nacional de Fortalecimento da Agricultura Familiar) em 1996. Não obstante, a agricultura familiar ganhou legitimidade social, política e acadêmica nos espaços de debate da agricultura e do mundo rural (SCHNEIDER, 2003).

Atualmente, nova visão cooperativista do século XX adentra ao espaço rural e as famílias começam um novo ciclo, passaram a unir-se nesse sistema associativo no qual pessoas livres se unem, somando suas forças de produção, sua capacidade de consumo e suas economias, no intuito de evoluírem econômica e socialmente, elevando seu padrão de vida e, igualmente, beneficiando a sociedade por meio do aumento e barateamento da produção, do consumo e do crédito (OLIVEIRA et al., 2020).

Ao buscarem soluções em conjunto, evoluem para decisões mais definitivas, aperfeiçoando a parceria, inicialmente informal, para uma forma de união organizada e associativa, onde teriam maiores chances de sucesso. Essa parceria fortaleceu o pequeno produtor e gerou discussões sobre os problemas vivenciados, como: pouca área de terras, baixa disponibilidade de recursos financeiros, assistência técnica insuficiente, compra de maquinário, mercado, entre outras dificuldades que os agricultores familiares enfrentam para produzir e escoar sua produção.

É notório que a agricultura familiar necessita de uma política de crédito especial, como já vinham reivindicando suas entidades representativas. $\mathrm{O}$ governo criou políticas de incentivo para minimizar e restaurar esta lacuna existente com programas de incentivos para a agroindústria, e linhas específicas visando atender esta demanda. $\mathrm{O}$ crédito rural, mal utilizado, pode aumentar a dependência dos agricultores, endividando-os, e a consequência é que alguns acabam perdendo o pouco de terras que ainda possuem. Por outro lado, estudos desta natureza permitem orientar a seleção de políticas públicas (extensão rural, crédito rural, pesquisa, ensino) compatíveis com as necessidades locais.

Como alternativa para esse cenário, alguns agricultores do Município de Itapuranga, começaram a fazer parte de alguns projetos de transição agroecológica. Os agricultores procuraram associar-se em cooperativas, onde se uniram para melhorar suas necessidades socioeconômicas e procurar formas de superar as dificuldades encontradas.

Segundo Costabeber (1998) a transição agroecológica pode ser evidenciada com a maior racionalização econômicoprodutiva baseado nas características biofísicas de cada agroecossistema, mas também pela mudança nas atitudes e nos valores dos atores sociais, relacionados ao manejo, a conservação dos recursos naturais, e ao progresso técnico e avanço científico. É fundamental avaliar os resultados socioeconômicos e ambientais dessas iniciativas, inclusive, por conta das escassas evidências na literatura, especialmente a nível regional, além de investigar os efeitos do cooperativismo na forma de o agricultor desenvolver suas atividades coletivamente. A hipótese norteadora da pesquisa foi que o sucesso das práticas agroecológicas está relacionado às dimensões econômicas e sociais dos agricultores, isto é, sua consciência socioambiental permite entender os processos de maneira mais ampla, identificando os fatores que levam ao próprio desenvolvimento. Este trabalho buscou descrever os avanços, benefícios e dificuldades da transição agroecológica do sistema de produção de frutas e hortaliças em cooperativa de agricultores familiares de Itapuranga, Goiás, bem como os custos de implantação do cultivo convencional e agroecológico e a rentabilidade auferida com a prática agroecológica.

\section{MATERIAL E MÉTODOS}

Itapuranga é um município goiano situado a 653 metros de altitude, com as seguintes coordenadas geográficas: Latitude: $15^{\circ}$ 32 ' 18" Sul, Longitude: $49^{\circ} 56^{\prime} 5^{\prime \prime}$ Oeste. Localizado a 170 quilômetros de Goiânia, na mesorregião Centro Goiano e microrregião de Ceres, Estado de Goiás.

Possui uma população de 26.125 habitantes no último Censo (IBGE, 2010), sendo que 19.090 (76,9\%) vivem no meio urbano e $5.742(23,1 \%)$ no meio rural. O município, situado a cerca de $170 \mathrm{~km}$ da capital do Estado de Goiás, ocupa uma área de $1.276,479 \mathrm{~km}^{2}$ e tem uma representação significativa. De acordo com os dados do Censo Agropecuário (IBGE, 2006) cerca de $94 \%$ dos estabelecimentos rurais de Itapuranga podem ser categorizados como pertencentes a agricultores familiares.

Para a realização dessa pesquisa, utilizou-se o delineamento de uma abordagem classificada como uma pesquisa qualitativa exploratória com uso do estudo de caso para a realização da pesquisa de campo. Como instrumentos de coleta de dados foram utilizados questionários estruturados e entrevistas não estruturadas, realizadas no último trimestre de 2017 e primeiro de 2018. Foram realizados encontros com os agricultores na feira do produtor rural e visitas a cooperativa, sendo a amostragem feita por conveniência. A entrevista foi parcialmente transcrita e analisada pelos autores. Os questionários foram baseados na versão utilizada em Vieira (2009), com as devidas adaptações 
para fins de adequação da realidade local e do objetivo do trabalho.

A Cooperativa dos Produtores Familiares de Itapuranga (COOPERAFI) foi fundada em 1998 e possuía 122 sócios, sendo 89 homens e 33 mulheres. Foi fundada com o objetivo de minimizar as disparidades existentes entre produtor e consumidor, já que auxilia na comercialização da produção dos agricultores e na compra de insumos em quantidades maiores, obtendo um maior poder de negociação. Em 2006, em parceria com a Universidade Federal de Goiás (UFG) e o Conselho Nacional de Desenvolvimento Científico e Tecnológico (CNPq), teve início o programa "Criação e Estabelecimento de Processos Agroecológicos no Município de Itapuranga". Nesse mesmo período, também foi aprovado o projeto de "Fruticultura Sustentável no Cerrado Goiano", por meio do programa Desenvolvimento e Cidadania da Petrobrás. Com esse projeto, em 2013, recebe a premiação da $12^{a}$ edição do Prêmio (Conselho Regional de Engenharia e Agronomia de Goiás (CREA - GO)). Em 2017 a COOPERAFI contava com 216 cooperados ativos e atua na comercialização do leite, fruticultura e hortaliças; assistência técnica; assim como na compra de insumos a preços mais acessíveis.

Analisou-se como os agricultores familiares geram seus empreendimentos, ou seja, que mecanismos criam para se inserir com o sistema mercadológico convencional, trabalhando com a autogestão, a agroecologia e a ajuda mútua. Portanto, além das variáveis socioeconômicas referentes aos agricultores, foram analisadas informações financeiras e verificadas práticas agrícolas. Foi analisada a organização dentro da cooperativa e como a transição agroecológica os ajudou a conseguir uma melhor qualidade de vida e maior competividade no mercado consumidor.

A amostragem foi composta por oito produtores que participaram da transição agroecológica. Desse grupo, se encontram quatro produtores que continuam empenhados na transição agroecológica e quatro desistentes. Do mesmo modo o gestor da cooperativa foi entrevistado, foram conversas informais ocasionadas após a realização dos questionários.

$\mathrm{O}$ grupo foi entrevistado individualmente contando com a colaboração dos chefes das famílias e suas esposas. A amostragem foi realizada por conveniência, e Os critérios de escolha foram sugeridos pelos entrevistados e realizados por indicação do líder da cooperativa e dos próprios cooperados entrevistados, que sugeriram outras pessoas a serem ouvidas. A maior parte das entrevistas foram gravadas, conforme autorização dos agricultores, que assinaram termo de consentimento.

Considerando que registros da Cooperativa mostravam que $76 \%$ dos agricultores inicialmente envolvidos com o projeto de agroecologia não deram prosseguimento, era necessário caracterizar a trajetória dessa agricultura familiar que, de alguma forma, não se adaptou às práticas agroecológicas repassadas aos agricultores. Para tanto, os custos (já existentes no projeto) de lavouras agroecológicas e convencionais foram confrontados para compreender se esse fator foi determinante no processo.

A pesquisa foi dividida em etapas. Em um primeiro momento, verificou-se a caracterização dos agricultores familiares, faixa etária dos agricultores familiares, composição da unidade familiar, escolaridade e se possuíam algum tipo de financiamento do governo federal. Também foi caracterizada a unidade rural, como as benfeitorias existentes na propriedade, se o produtor trabalha com a produção leiteira e as principais atividades produtivas. Foram abordadas as atividades agroecológicas, se as famílias trabalham com os projetos de reestruturação, quais são as técnicas mais utilizadas, tipos de cultivo, níveis de renda antes e após a adoção dos preceitos agroecológicos e participação dessa produção na renda total, as dificuldades encontradas ao sair do cultivo tradicional, participação em cursos e se possuem um público específico para a comercialização. Concluída essa etapa, prosseguem para a parte da cooperativa e sua gestão, para tentarmos compreender por que a mudança de gestor supostamente ocasionou o estancamento das práticas agroecológicas e se a cooperativa possui uma gestão participativa junto aos agricultores familiares. A maior parte dessas perguntas foram traduzidas em variáveis quantitativas, apresentadas e analisadas ao longo da próxima seção.

Os resultados quantitativos foram analisados por estatística descritiva. Ademais, houve comparação entre os diferentes grupos, da maneira a identificar as diferenças entre os agricultores de sistemas agroecológicos e os agricultores com sistema tradicional de plantio e cultivo. As ideias apresentadas e discussões provenientes das entrevistas foram analisadas permitindo maior aprofundamento dos resultados quantitativos.

\section{RESULTADOS E DISCUSSÃO}

Os agricultores que participaram da transição agroecológica no município de Itapuranga frisam a importância da cooperativa pela conquista da liberação dos recursos, de acordo com a transcrição de uma das entrevistas, "a cooperativa com seu antigo gestor foi quem se organizou e se mobilizou socialmente em prol dos pequenos produtores e com essa mobilização em 2009 foi viabilizado para os produtores de Itapuranga a maior liberação de crédito rural e foi através dessa organização e esforço do antigo gestor senhor que fomos contemplados com os projetos de transição agroecológica (UFG) e de produção frutícola sustentável (Petrobrás)". Com o crédito rural os produtores melhoraram suas lavouras e construíram algumas benfeitorias, como galpão para colocarem suas colheitas, poço para irrigarem as suas lavouras, adquiriram alguns animais para melhorarem sua renda mensal e automóvel para transportar sua mercadoria. Segundo Knorek (2011 p. 50), “o crédito é o motor da economia e o agronegócio vem se beneficiando com linhas específicas, a taxas de juros controladas, e com medidas emergenciais de suporte para os efeitos da crise financeira mundial". Com essa abertura do crédito rural para o município a cooperativa começou a desenvolver os projetos de transição agroecológica.

De acordo com Marin e Matos (2009 p. 199), “o sistema de produção desenvolvido pelos agricultores familiares que se estabeleceram em Itapuranga esteve orientado para a diversificação produtiva, visando atender as necessidades alimentares do grupo familiar e a comercialização de excedentes". Em concordância Schneider (2003), afirma que os agricultores familiares têm como características mão de obra basicamente familiar, contratando mão de obra complementar nos períodos de muito trabalho; organização do processo produtivo é realizada pela família; produção diversificada, com 
objetivo de ocupar melhor a área, a mão de obra familiar e aumentar a renda; cuidados com a conservação dos recursos naturais, pois dependem totalmente destes para a reprodução da família.
Inicialmente, notou-se que dos oito entrevistados cinco são cooperados de longa data da COOPERAFI e os outros três foram cooperados, porém deixaram a cooperativa após a mudança de gestão. Com relação às atividades adotadas nas propriedades, há uma relativa diversidade de cultivos (Tabela 1).

Tabela 1. Principais cultivos agroecológicos da agricultura familiar cooperada em Itapuranga, Goiás, $2017 / 2018$.

\begin{tabular}{|c|c|c|c|c|c|}
\hline \multicolumn{3}{|c|}{ Atividades dos agricultores que utilizam a agroecologia } & \multicolumn{3}{|c|}{ Atividades dos agricultores desistentes } \\
\hline Tipo de cultivo & $\mathrm{N}^{\mathrm{o}}$ de agricultores & $\%$ & Tipo de cultivo & $\mathrm{N}^{\mathrm{o}}$ de agricultores & $\%$ \\
\hline Banana & 3 & 30 & Banana & 2 & 29 \\
\hline Mamão & 3 & 30 & Mamão & 1 & 13 \\
\hline Hortaliças & 3 & 30 & Hortaliças & 2 & 29 \\
\hline
\end{tabular}

Dos agricultores que utilizam a agroecologia nenhum desempenha menos do que três atividades em sistema de manejo agroecológico. Nesse grupo nota-se forte tendência de aceitação do cultivo do mamão, banana e das hortaliças.

O maracujá já requer mais mão de obra e com isso se torna mais dispendioso. No entanto, somente aqueles que investiram em tecnologia e orientação técnica conseguiram sobreviver frente à suscetibilidade desta cultura às doenças e pragas, por utilizar insumos de alto valor aquisitivo e de ser necessário atender à exigência de qualidade dos mercados a que se destina
(MELETTI, 2011). Enquanto no primeiro caso as atividades de manejo agroecológico não eram inferiores a três em nenhum dos pesquisados, em se tratando dos desistentes a implantação de cultivo agroecológico à época da participação nos projetos não ultrapassava duas modalidades. Quanto às técnicas agroecológicas mais utilizadas pelos agricultores que permaneceram no sistema, podemos observar na Tabela 2, uma maior utilização dos defensivos naturais, adubação verde e biofertilizante líquido.

Tabela 2. Principais técnicas agroecológicas dos agricultores familiares cooperados em Itapuranga, Goiás, $2017 / 2018$.

\begin{tabular}{|c|c|c|c|c|c|}
\hline \multicolumn{3}{|c|}{ Técnicas dos agricultores que utilizam a agroecologia } & \multicolumn{2}{|c|}{ Técnicas dos agricultores desistentes } & \multirow[b]{2}{*}{$\%$} \\
\hline Técnicas agroecológicas & $\mathrm{N}^{\circ}$ de agricultores & $\%$ & Técnicas agroecológicas & $\mathrm{N}^{\mathrm{o}}$ de agricultores & \\
\hline Adubação Verde & 4 & 20 & Adubação Verde & 4 & 37 \\
\hline Adubação Orgânica & 3 & 15 & Adubação Orgânica & 3 & 27 \\
\hline Compostagem Sólida & 2 & 10 & Sistema Agroflorestal & 2 & 18 \\
\hline Biofertilizante Líquido & 4 & 20 & & & \\
\hline
\end{tabular}

Práticas de adubação verde e de sistemas agroflorestais que, para além da agroecologia, configuram-se como garantia de maior estabilidade ao agroecossistema e às atividades produtivas nele desenvolvidas (MARIN, 2009). Além das tecnologias citadas acima para a conservação da biodiversidade, estão o uso do solo de acordo com a capacidade de uso, adubação verde, plantas recuperadoras, consorciação, rotação de culturas, uso de quebra ventos, pastoreio racional, plantio direto sem dessecação, sistemas agroflorestais, alelopatia, controle biológico e uso de planta protetoras.

A manutenção da biodiversidade e o conhecimento sobre sucessões naturais e plantas indicadoras estão no contexto das tecnologias de base ecológica (PAULUS; SCHLINDWEIN, 2001).

Os produtores acreditam que utilizando práticas agrícolas não agressivas, gerando alimentos saudáveis, livres de resíduos tóxicos e com qualidade ecológica, a agroecologia é capaz de recuperar o agroecossistema tão degradado nos últimos anos com práticas de cultivos tradicionais e com a utilização de agrotóxicos. Ribeiro e Freitas (2012), afirma que a agroecologia “[...] É produzir alimentos sob outro paradigma, holístico, com práticas agrícolas não agressivas à vida no seu conjunto, gerando alimentos saudáveis, livres de resíduos tóxicos e com qualidade ecológica”.

Os agricultores desistentes utilizaram menos técnicas agroecológicas e ressaltaram as dificuldades relacionadas ao manejo, o controle de pragas aparece como uma dificuldade importante, sendo que para três pesquisados este ponto é determinante para o insucesso da experiência agroecológica. Para os demais o controle de praga só é mais um dos problemas e dificuldades encontradas, foi citado também à dificuldade em obter adubo orgânico (1 agricultor); os problemas de suprimento de adubo orgânico à pouca disponibilidade de mudas e/ou sementes adequados ao cultivo agroecológico (2 agricultores).

Contudo, quando questionados se trabalham com a produção de leite ou apenas agricultura, verifica-se na Tabela 3, que a pecuária leiteira desempenha papel de destaque em áreas pequenas em consórcio com fruticultura e horticultura. A produção de leite é um acréscimo na renda das famílias, o leite é comercializado na feira do produtor através do produto in natura ou na obtenção de doces, requeijão, queijo e alguns produtores que entregam para laticínios. Os principais produtos hortícolas cultivados foram: tomate, pimentão, pimenta, abóbora, pepino, melancia, repolho e folhosas. Assim, os agricultores familiares 
de Itapuranga adequaram seus sistemas de produção ao desenvolvimento conjugado da fruticultura, horticultura e bovinocultura de leite (MARIN; MATOS, 2009).

A COOPERAFI, através de recursos obtidos com os projetos adquiriu tanques resfriadores para coletar o leite de cooperados e não cooperados para ser revendido posteriormente a grandes cadeias de laticínios a preços mais elevados devido ao maior volume comercializado (Tabela 3 ).

Tabela 3. Principais atividades produtivas da agricultura familiar cooperada em Itapuranga, Goiás, $2017 / 2018$.

\begin{tabular}{lccc}
\hline Área da propriedade (ha) & Atividade principal - fator renda & $\begin{array}{l}\mathrm{N}^{\circ} \text { agricultores } \\
\text { (não desistentes) }\end{array}$ & $\begin{array}{c}\mathrm{N}^{\mathrm{a}} \\
\text { (desistentes) }\end{array}$ \\
\hline Até 5 ha & pecuária/hortaliças & - & 1 \\
Até 5 ha & pecuária/fruticultura & - & 1 \\
Até 5 ha & fruticultura/horticultura & - & 1 \\
Até 15 ha & pecuária/hortaliças & 1 & 1 \\
Até 15 ha & pecuária/fruticultura & 1 & - \\
Até 15 ha & fruticultura/horticultura & 2 & - \\
\hline
\end{tabular}

Podemos observar que das três propriedades com área de até 15 hectares, em apenas um caso a pecuária leiteira não é citada como importante componente da renda. Dentre as restantes, a pecuária leiteira é predominante em uma propriedade, associada com a horticultura em outra e com a fruticultura. Os sistemas de cultivo caracterizavam se pela produção diversificada a estratégia produtiva desses agricultores se baseia em uma multiplicidade de atividades que visam garantir a reprodução da unidade familiar (CAUME, 2005, p. 28).

Outrora o cultivo de frutas foi responsável pelo principal gerador de renda da economia local, iniciou-se com o maracujá, $\mathrm{O}$ crescimento do mercado fez com que uma grande quantidade de agricultores aderisse a esse cultivo. Após, passou a dividir espaço com a banana na produção comercial e que hoje caminha para uma maior diversificação, onde merece destaque a cultura do mamão.

Buscando uma melhor compreensão ao observar os custos e as receitas para averiguar se houve relação com o estancamento das práticas agroecológicas, e se a produção com as novas técnicas aumentou as receitas e diminuíram os custos de produção, observem os dois sistemas de cultivo, tanto o tradicional como o agroecológico. Os dados dos custos são anotações e relatórios feitos pelos agricultores e técnicos responsáveis pelos projetos. Inicialmente como podem observar na Tabela 4, foram escolhidas as frutas de maiores cultivos a bananicultura e mamonicultura, o ciclo produtivo é considerado de médio prazo, no máximo um ano, porém foram considerados seis meses, pois é o período que as plantas necessitam de maiores cuidados.

Tabela 4. Custo de implantação de um hectare de mamão em cultivo convencional da agricultura familiar cooperada em Itapuranga, Goiás, 2017/2018.

\begin{tabular}{|c|c|c|c|c|}
\hline $\begin{array}{c}\text { Especificação } \\
\text { rãom }\end{array}$ & Quantidade & Unidade & Custo unitário $(\mathrm{R} \$)$ & Valor total $(\mathrm{R} \$)$ \\
\hline \multicolumn{5}{|l|}{ Aração, gradagem e } \\
\hline Calcário & 3 & Tonelada & 60,00 & 180,00 \\
\hline Adubo mineral & 25 & Saco de $40 \mathrm{~kg}$ & 40,00 & $1.000,00$ \\
\hline Adubo Orgânico & 35 & $\mathrm{~m}^{3}$ & 40,00 & $1.400,00$ \\
\hline \multicolumn{5}{|l|}{ Adubo Mineral- Cloreto de } \\
\hline Adubo Mineral -Sulfato de Amônio & 15 & Saco de $50 \mathrm{~kg}$ & 35,00 & 525,00 \\
\hline Adubo Mineral - Bórax & 2 & $\mathrm{~kg}$ & 5,00 & 10,00 \\
\hline \multicolumn{5}{|l|}{$\begin{array}{l}\text { Cova, adubação básica e cobertura, } \\
\text { capina manual, irrigação e desbaste }\end{array}$} \\
\hline de plantas & 150 & Homem/dia & 35,00 & $5.250,00$ \\
\hline Total & & & & $11.075,00$ \\
\hline
\end{tabular}

Das lavouras frutícolas analisadas, o mamão é a que apresentou os menores custos de implantação e possuía atratividade por ter uma boa saída para o mercado. Tornou-se também atrativo, porque requer uma manutenção mais simples facilitando o manejo.
Observa-se na Tabela 5, os custos para implantação do cultivo agroecológico, assim podem traçar uma comparação aos dois sistemas em relação ao custo. 
Tabela 5. Custo de implantação de um hectare de mamão em cultivo agroecológico da agricultura familiar cooperada em Itapuranga, Goiás, 2017/2018.

\begin{tabular}{|c|c|c|c|c|}
\hline \multirow{2}{*}{\multicolumn{5}{|c|}{$\begin{array}{c}\text { Especificação } \\
\text { Aracão, gradagem e }\end{array}$}} \\
\hline & & & & \\
\hline Aplicação de calcário & 12 & Hora/Máquina & 80,00 & 960,00 \\
\hline Calcário & 3 & Tonelada & 60,00 & 180,00 \\
\hline Mudas & 5.000 & $\mathrm{Um}$ & 0,30 & $1.500,00$ \\
\hline Adubo - Cama de Frango & 0,5 & Tonelada & 160,00 & 80,00 \\
\hline $\begin{array}{l}\text { Cova, adubação básica e cobertura, } \\
\text { capina manual, irrigação e desbaste } \\
\text { de plantas } \\
\text { Total }\end{array}$ & 210 & Homem/dia & 35,00 & $\begin{array}{l}7.350,00 \\
10.070,00\end{array}$ \\
\hline
\end{tabular}

Conforme notamos nas Tabelas 4 e 5 , os custos de implantação das culturas são bastante próximos, a ponto de não justificarem, por si só, a adoção de um ou outro modo de produção, ou até mesmo, o abandono das práticas agroecológicas em relação aos custos. No cultivo convencional, a inversão de capital (insumos e maquinário) na implantação da lavoura representou $64 \%$ do custo total. Trata-se de um sistema produtivo poupador de mão de obra, mas que exigiu um maior desembolso inicial, tendo em vista que o emprego de mão de obra é menos intensivo no período de implantação do que os insumos e a tecnologia. No cultivo do mamoeiro agroecológico, as despesas homem/dia alcançaram $73 \%$ do custo total de implantação, levando ao alto custo da mão de obra. Esse sistema requer maiores cuidados com ervas invasoras, a colocação gradual do adubo empregado e a incorporação de matéria orgânica revirando-se a terra da plantação, atividades que são totalmente manuais. Portanto, importar máquinas de países que tem agricultura familiar pode ser uma saída. Na comparação dos sistemas, a implantação da mamonicultura agroecológica foi $11 \%$ mais barata do que sua similar em cultivo convencional. Em um depoimento reconhece uma forte adesão a mamonicultura agroecológica devido a menor propensão às doenças, como cita: "uma vez que se controlam as pragas elas não voltam". Em outros tempos pragas locais recaíam, sobretudo, na cultura do maracujá e, também, devido a maior perenidade dos mamoeiros em relação a outras frutas plantadas na região.

Dessa forma, os produtores foram deixando os maracujazeiros e aderindo a mamonicultura e bananicultura, pois essas culturas superaram o maracujá devido aos problemas que envolvem a proliferação de pragas. Veremos na Tabela 6, o cultivo da banana que também se tornou uma cultura forte para os agricultores familiares do município.

Tabela 6. Custo de implantação de um hectare de banana em cultivo convencional na agricultura familiar cooperada de Itapuranga, Goiás, 2017/2018.

\begin{tabular}{|c|c|c|c|c|}
\hline \multirow{2}{*}{\multicolumn{5}{|c|}{$\frac{\text { Especificação }}{\text { Aração, gradagem e }}$}} \\
\hline & & & & \\
\hline Aplicação de calcário & 12 & Hora/Máquina & 80,00 & 960,00 \\
\hline Calcário & 3 & Tonelada & 60,00 & 180,00 \\
\hline Mudas & 1.666 & Um & 2,50 & $4.165,00$ \\
\hline Adubo mineral & 30 & Saco de $40 \mathrm{~kg}$ & 40,00 & $1.200,00$ \\
\hline Adubo Orgânico & 40 & $\mathrm{~m}^{3}$ & 40,00 & $2.280,00$ \\
\hline Adubo Mineral- Cloreto de Potássio & 12 & Saco de $50 \mathrm{~kg}$ & 50,00 & 600,00 \\
\hline Adubo Mineral -Sulfato de Amônio & 37 & Saco de $50 \mathrm{~kg}$ & 35,00 & $1.295,00$ \\
\hline $\begin{array}{l}\text { Cova, adubação básica e cobertura, } \\
\text { capina manual, irrigação e desbaste } \\
\text { de plantas } \\
\text { Total }\end{array}$ & 150 & Homem/dia & 35,00 & $\begin{array}{l}5.250,00 \\
16.450,00\end{array}$ \\
\hline
\end{tabular}

O cultivo da banana se diverge do cultivo do mamão em questão de quantidade, pois requer um número maior de mudas, porém, uma quantidade maior de adubo orgânico. A bananeira exige um espaçamento bem maior entre uma planta e outra, dada sua composição em forma de moita, onde vários caules produzem cachos distintos e que, após a colheita requerem corte para o desenvolvimento de nova leva de caules produtivos. Por esse motivo a bananeira requer mais matéria orgânica e a renovação constante desta em cada cova.

Quanto ao peso percentual representado pelos insumos e itens de tecnologia necessários à produção, a bananicultura convencional constou de $59 \%$ dos investimentos de implantação nesses quesitos. A área plantada com banana requer menos cuidados no que tange à roçagem, já que essas possuem folhas largas que fazem sombra e barram a proliferação de ervas invasora. Em compensação, as bananeiras são bastante exigentes quanto ao desbaste, porque a não remoção de caules que já produziram facilita o aparecimento de fungos e impede os caules jovens de aparecerem. Na Tabela 7 podemos observar a bananicultura em cultivo agroecológico e analisar seus custos comparados ao convencional. 
Tabela 7. Custo de implantação de um hectare de banana em cultivo agroecológico na agricultura familiar cooperada de Itapuranga, Goiás, 2017/2018.

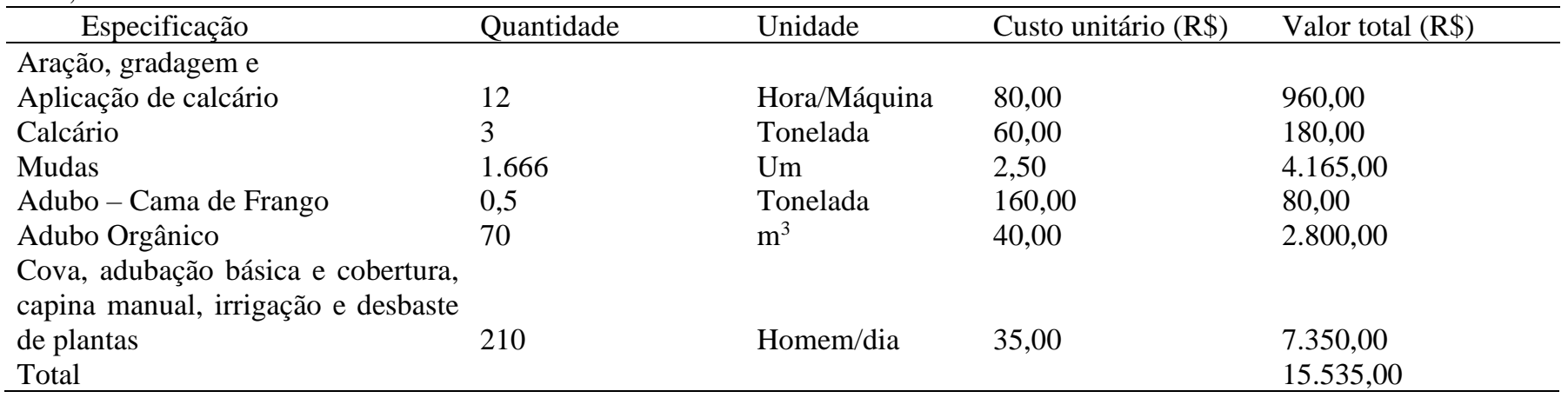

A lavoura de banana agroecológica teve $48 \%$ de seu custo de implantação baseado na despesa com mão de obra. Esse peso percentual menor em comparação com a mamonicultura agroecológica se explica o fato de que muitos agricultores afugentam o cultivo da banana comercialmente, mesmo se tratando do cultivo convencional as bananeiras necessitam de mão de obra intensiva. Ainda assim, o cultivo da banana cresceu, pois é um produto muito comercializado na feira do produtor rural e, também, é matéria-prima de grande quantidade de doces e compotas que agregam valor à produção e tem uma ótima saída no mercado local.

Grande parte dos agricultores familiares que aderiram aos projetos de transição agroecológica possuía experiência no cultivo de frutas. Muitos com o maracujá como o carro chefe da propriedade. Dessa forma, manter o sistema convencional ou tentar a transição agroecológica não acarretou altos custos aos produtores, pois o retorno econômico era praticamente o mesmo, mas, as práticas agroecológicas destacavam como um diferencial a mais na comercialização. Para Nunes da Silva et al. (2009, p. 3022), "os processos de transição agroecológica constituem-se em desafios para a sustentabilidade das regiões rurais".

No caso da horticultura, a experiência não foi tão significativa quanto à fruticultura. Os produtores já possuíam suas hortas para o consumo pessoal. Quando iniciaram o trato dessas lavouras para o comércio exigiu-se uma mão de obra intensa e contínua.

Para estudo desse sistema produtivo, a experiência foi em uma área menor de 1 ha (fruticultura) para 0,5 ha. Outro diferencial foi o tempo, para a horticultura, o ciclo produtivo foi bem menor, como nos casos da alface e da couve que serão aqui abordados. Diante desse retrato as hortaliças caracterizadas como plantas de curta duração, no máximo de três meses. A seguir na Tabela 8, os custos ocorridos nas lavouras de hortaliças (alface e couve).

Tabela 8. Custo de implantação de 0,5 hectares de horticultura (alface e couve) em cultivo convencional na agricultura familiar cooperada de Itapuranga, Goiás, 2017/2018.

\begin{tabular}{|c|c|c|c|c|}
\hline \multirow{2}{*}{\multicolumn{5}{|c|}{$\begin{array}{c}\text { Especificação } \\
\text { Aracão, gradagem e }\end{array}$}} \\
\hline & & & & \\
\hline Calcário & 1 & Tonelada & 60,00 & 60,00 \\
\hline Adubo mineral & 2 & Saco de $25 \mathrm{~kg}$ & 30,00 & 60,00 \\
\hline Adubo Orgânico & 20 & $\mathrm{~m}^{3}$ & 40,00 & 800,00 \\
\hline $\begin{array}{l}\text { Construção de canteiros, adubação } \\
\text { básica e cobertura, capina manual, } \\
\text { irrigação e desbaste das plantas } \\
\text { Total }\end{array}$ & 200 & Homem/dia & 35,00 & $\begin{array}{l}7.000,00 \\
13.320,00\end{array}$ \\
\hline
\end{tabular}

A mão de obra da horticultura é muito intensa por isso se torna mais dispendiosa no caso analisado, $53 \%$ de todo a despesa de implantação da horta se deve a esse fator. Necessita de todo um cuidado com as folhagens na hora da irrigação para não estragar os canteiros e as próprias folhas. O controle de plantas invasoras é praticamente diário e feito sem o auxílio de nenhuma ferramenta, é realizado manualmente. Há ainda o trabalho com a preparação do viveiro de mudas e a posterior mudança destas para o canteiro. No caso da alface, as folhas mais próximas ao chão geralmente apodrecem e necessitam de remoção, tanto sendo retiradas da horta quanto incorporadas ao solo como cobertura e adubo orgânico. Na Tabela 9, a seguir os dados referentes ao cultivo agroecológico.
Analisando a Tabela 9, observamos que os insumos necessários para as duas produções são os mesmos, portanto o que diferencia é a mão de obra e o que se tornou as hortaliças agroecológicas com os custos de implantação mais alto do que as similares convencionais (7\%). Justificam essa diferença quando se leva em conta que a ausência de agrotóxicos torna o controle de pragas dificultado na produção agroecológica, além do que, o não uso de adubo retarda o desenvolvimento da planta e requerem cuidados por mais tempo e, portanto, maior uso de mão de obra. Quando questionados se utilizam toda a terra com as práticas agroecológicas, concluem que até em 15 ha, que foi a proporção das terras que aderiram ao experimento, de $20 \%$ a $40 \%$ da área é dedicada a agroecologia (Tabela 10). 
Tabela 9. Custo de implantação de 0,5 hectares de horticultura (alface e couve) em cultivo agroecológico na agricultura familiar cooperada de Itapuranga, Goiás, 2017/2018.

\begin{tabular}{|c|c|c|c|c|}
\hline Especificação & Quantidade & Unidade & Custo unitário ( $\mathrm{R} \$$ ) & Valor total $(\mathrm{R} \$)$ \\
\hline Aração, gradagem e & & & & \\
\hline Aplicação de calcário & 5 & Hora/Máquina & 80,00 & 400,00 \\
\hline Calcário & 1 & Tonelada & 60,00 & 60,00 \\
\hline Sementes & 20 & Lata $100 \mathrm{~g}$ & 250,00 & $5.000,00$ \\
\hline Adubo Orgânico & 20 & $\mathrm{~m}^{3}$ & 40,00 & 800,00 \\
\hline $\begin{array}{l}\text { Construção de canteiros, adubação } \\
\text { básica e cobertura, capina manual, } \\
\text { irrigação e desbaste das plantas } \\
\text { Total }\end{array}$ & 230 & Homem/dia & 35,00 & $\begin{array}{l}8.050,00 \\
14.310,00\end{array}$ \\
\hline
\end{tabular}

Tabela 10. Participação da agroecologia na composição da renda de agricultores familiares cooperados em Itapuranga, Goiás, 2017/2018.

\begin{tabular}{lccc}
\hline Área da propriedade (ha) & $\begin{array}{l}\text { Participação da agroecologia na renda } \\
\text { total (\%) }\end{array}$ & $\begin{array}{l}\mathrm{N}^{\circ} \text { de agricultores } \\
\text { (não desistentes) }\end{array}$ & $\begin{array}{l}\mathrm{N}^{\mathbf{2}} \\
\text { (desistentes) }\end{array}$ \\
\hline Até 5 ha & Até 20 & - & - \\
Até 15 ha & Até 20 & 1 & - \\
Até 15 ha & 20 a 40 & 2 & 1 \\
Até 15 ha & 40 a 60 & 1 & - \\
\hline
\end{tabular}

A maior parte dos agricultores não desistentes das práticas agroecológicas concorda que suas receitas aumentaram com a transição agroecológica. "Os custos não foram tão altos $e$ conseguimos um bom rendimento" (Agricultor 1). Dentre os entrevistados desistentes, apenas uma ocorrência de aumento na receita. Segundo esse agricultor, as atividades agroecológicas lhe proporcionaram um aumento na renda da ordem de 30\%. Os demais não tiveram acréscimo na receita, os projetos agroecológicos se tornam de fato viáveis pelo custo mais baixo de preparação e cultivo, porém, requerem um número muito grande de mão de obra, principalmente para a horticultura. Contudo, observaram que os agricultores desistentes e que não tiveram acréscimo em suas rendas possuem até 5 ha de terras e o único desistente que ainda obteve os $30 \%$ oriundo da agroecologia possui 15 ha de terra. Consideram uma variável importante, pois acreditam que se tivessem terras maiores haveria mais diversificação (Tabela 11).

Tabela 11. Faixa de renda (salários mínimos) de agricultores familiares cooperados de Itapuranga, Goiás, 2017/2018.

\begin{tabular}{llcc}
\hline $\begin{array}{l}\text { Tamanho da propriedade } \\
\text { (ha) }\end{array}$ & Faixa de renda atual (salários) & $\begin{array}{l}\mathrm{N}^{\circ} \text { de agricultores } \\
\text { (não desistentes) }\end{array}$ & $\begin{array}{l}\mathrm{N}^{\circ} \\
\text { (desistentes) }\end{array}$ \\
\hline Até 5 ha & Entre 1 e 2 salários & - & 2 \\
Até 15 ha & Entre 1 e 2 salários & 1 & 2 \\
Até 15 ha & Entre 2 e 3 salários & 3 & - \\
\hline
\end{tabular}

De acordo com os agricultores, apesar de não perguntada explicitamente, é notória a satisfação dos que trabalham com a agroecologia, pois proporcionam uma maior renda para os produtores e, principalmente, expressam o contentamento nos discursos das entrevistas. Em contrapartida, os agricultores desistentes afirmam que as práticas requerem mais mão de obra e os salários que recebem não são suficientes para atenderem a demanda.

Outro ponto importante é a comercialização, pois os agricultores que participaram do projeto tiveram seus produtos designados para o PNAE e seus excedentes comercializados na Feira do Produtor Rural, os agricultores que trabalham com a fruticultura sua colheita era designada para o projeto PRAFICAR e seus excedentes vendidos na feira do produtor. Segundo argumentam, "os consumidores têm preferência pelos alimentos de melhor aparência externa, como, tamanho, cor, ausência de fissuras e no caso dos agroecológicos, são produtos menores e mais feios". O sistema agroecológico dispensa o uso de agrotóxicos e fertilizantes químicos sintéticos, agressivos à saúde e ao meio ambiente. "Procura uma interação entre o agricultor e consumidor, de forma que atenda às necessidades das partes envolvidas e fomente a corresponsabilidade" (PENTEADO, 2007, p. 43). E mesmo com essas características, a produção agroecológica na feira é a primeira a acabar, pois existe uma demanda grande, apesar dos consumidores quererem pagar o mesmo preço aos demais produtos advindos do cultivo convencional. Os agricultores desistentes afirmam que o aspecto externo dos alimentos agroecológicos é um ponto desfavorável a comercialização, visto que os consumidores preferem os alimentos de aparência melhor e que são de mesmo valor (preço). Alegam que a maior dificuldade de comercialização ocorreu após a troca de gestor da cooperativa, pois assim deixaram de entregar os alimentos para o programa PNAE.

$\mathrm{Na}$ ocasião que foram questionados sobre as dificuldades encontradas observaram que no início da transição a maior dificuldade foi o controle de pragas. Sair de um modelo 
convencional sem o uso do agrotóxico gera algumas dificuldades, mas, a pior delas, o controle das pragas, na ausência de agrotóxicos, recai altamente no manejo (preparação e aplicação de caldas, remoção manual de plantas invasoras). Sintetiza Altieri (1989 p. 18-19), que "a produção sustentável em um agroecossistema deriva do equilíbrio entre plantas, solos, nutrientes, luz solar, umidade e outros organismos coexistentes".

Em relação às dificuldades encontradas para dar continuidade ao sistema após os encerramentos dos projetos, todos afirmam que foi o apoio técnico.

Notaram que enquanto os projetos estavam vigentes os agricultores familiares tiveram todo apoio técnico necessário, porém com o encerramento dos projetos, se quisessem o apoio técnico os agricultores pagariam pelas visitas técnicas e muitos deles não se julgavam com condições para manter as visitas. Outro fato importante quanto ao apoio técnico segundo consta, havia alta rotatividade de pessoal e com isso, mudava-se de assistente, sendo que cada um era de um jeito e os tratavam de maneiras diferentes.

A COOPERAFI na gestão anterior desenvolveu um papel social junto aos agricultores familiares, desde 2010 comercializa seus produtos (frutas, verduras e polpas de frutas) com o PNAE em vários municípios entre eles Goiânia com a Prefeitura
Municipal desde 2012. O foco foi voltado ao agricultor familiar, em busca de melhorar sua renda, inseri-lo na sociedade e no mercado. Acolheu os produtores de leite, foi em busca de beneficiamentos, cursos, financiamentos e melhores preços para o pequeno pecuarista. Em janeiro de 2016 inicia a nova gestão da COOPERAFI, a cooperativa como muitos afirmaram nas entrevistas e questionários tornou-se uma gestão voltada ao leite. Os agricultores familiares que trabalham com agroecologia se viram excluídos e ressaltaram a troca de gestor como sendo um fator negativo para que continuassem utilizando a agroecologia.

Os agricultores desistentes ressaltaram da mesma forma outro fator negativo, que foi a gerência dos projetos. Disseram que o tempo exigido para os resultados dos dois projetos agroecológicos era de quatro anos. Consideramos o tempo um elemento importante, se fossem a longo prazo, isto é, de cinco a seis anos, teríamos o maior número de resultados positivos, pois a teoria é uma coisa e a prática e os resultados, bem mais complexos.

Quando questionados se a cooperativa possui uma gestão eficiente voltada para os agricultores familiares, podemos observar na tabela 12, que os agricultores e pecuaristas afirmam que sim, no entanto somente entre os que trabalham com agricultura (sem pecuária) não concordam.

Tabela 12. Gestão cooperativista participativa e eficiente

\begin{tabular}{llcc}
\multicolumn{1}{c}{ Tabela Likert } & Atividade principal - Produção & $\begin{array}{c}\mathrm{N}^{\mathbf{o} d e} \text { agricultores } \\
\text { (não desistentes) }\end{array}$ & $\mathrm{N}^{\mathbf{o}}$ agricultores desistentes \\
\hline Concordo totalmente & Pecuária/Hortaliças/Fruticultura & - & - \\
Concordo em parte & Pecuária/Hortaliças/Fruticultura & 2 & 3 \\
Discordo em parte & Pecuária/Hortaliças/Fruticultura & 0 & - \\
Indiferente & Pecuária/Hortaliças/Fruticultura & - & - \\
Discordo totalmente & Fruticultura/horticultura & 2 & 1 \\
\hline
\end{tabular}

Observa-se na tabela 12, que mesmo os produtores que trabalham com a pecuária tanto quanto agricultura, concordam que a atual gestão da cooperativa é falha no quesito agricultura e principalmente no que diz respeito à agroecologia. "A cooperativa ainda não abandonou os agricultores porque têm as polpas de frutas e precisam da nossa colheita para a agroindústria de processamento" (Produtor 1). Os que concordam em parte exercem os dois segmentos e mesmo assim exigem mais atenção voltada aos seus cultivos. Os agricultores que discordaram totalmente já não fazem parte da cooperativa, por falta de apoio a agroecologia acabaram saindo e afirmam que é uma gestão voltada a pecuária leiteira. A carência de planejamento a curto e médio prazo, associado a uma fraca capacidade de investimento de capital, cada vez mais, as cooperativas, independentemente de onde estejam localizadas, terão que se capacitar e reformular suas práticas democráticas no processo de autogestão (ABREU et al., 2008).

O agricultor que trabalha com o sistema agroecológico se sente encorajado a continuar nesse caminho e aperfeiçoam seus processos mesmo sem o apoio da cooperativa. Do outro lado, os agricultores desistentes das práticas não dão continuidade aos projetos, embora ainda utilizem técnicas que aprenderam a exemplo do uso de biofertilizante e o manejo ecológico de pragas em caráter adicional às práticas convencionais. Através desses fatos reintegra o porquê desse grupo de quatro agricultores que desistiram dos projetos, apontam o manejo e quantidade de mão de obra exigida como fator determinante não possuem recursos financeiros suficientes, sem boas perspectivas de renda, comercialização, em vista disso, modificar e manter uma prática muito diferente do convencional em médio prazo é desafiador. Mesmo com as dificuldades e resistência de deixarem um sistema tradicional, para inserir uma nova prática, as famílias que continuam utilizando agroecologia em suas terras afirmam que o projeto proporcionou avanços. Apesar disso, ainda com as desistências observa-se que os agricultores ficaram mais conscientes sobre as questões ambientais e mesmo que não utilizem completamente os manejos algum aprendizado ficou e está sendo empregado em suas terras.

\section{CONCLUSÕES}

A mão de obra foi o fator limitante apontado pelos os agricultores cooperados de Itapuranga, isto é, tanto os que adotaram a agroecologia, quanto os desistentes. Assim, escassez de mão de obra e sua utilização intensiva são fatores limitantes para a produção agroecológica. Apesar das limitações, a transição desenvolvida em Itapuranga representa uma oportunidade de desenvolvimento de novas práticas sustentáveis na agricultura familiar, como redução no uso de insumos químicos e agrotóxicos, melhores práticas de manejo dos processos agroecológicos. 
Os avanços, benefícios e dificuldades da transição agroecológica do sistema de produção de frutas e hortaliças em cooperativa de agricultores familiares de Itapuranga estão relacionados com as dimensões econômicas, sociais e ambientais, com processos mais amplos que levem ao desenvolvimento socioambiental. Assim, o sucesso não se deu apenas pela mensuração dos custos de implantação do cultivo convencional e agroecológico e pela rentabilidade auferida com a prática agroecológica.

$\mathrm{O}$ sucesso dos agricultores que fizeram a transição do sistema de produção convencional vis-à-vis agroecológico resultou, sobretudo, em maiores ganhos econômicos. Em parte, provenientes do recebimento de insumos e assistência técnica da cooperativa. Os produtores que possuíam mais recursos financeiros, mão de obra qualificada, consciência social e ambiental foram os que conseguiram maior agregação de valor ao produto final.

O sucesso dos agricultores que fazem a transição do sistema de produção convencional vis-à-vis agroecológico foi além do recebimento de insumos e assistência técnica da cooperativa. Os produtores que possuíam recursos financeiros, mão de obra qualificada, consciência social e ambiental foram os que conseguiram agregação de valor ao produto final.

\section{REFERÊNCIAS}

ABREU, B. S.; BARACUHY NETO, G. M.; ARAÚJO, P. S.; BEZERRA, P. T. C.; FERNANDES NETO, S. Cooperativismo como alternativa para o desenvolvimento regional - o exemplo da COAPECAL. Revista de Geografia, v. 25, n.3, p. 72-84, 2008.

ALTIERI, M. A. Agroecologia: as bases científicas da agricultura alternativa. 2. ed. Rio de Janeiro: PTA- FASE, 1989. $240 \mathrm{p}$.

BOLFE, L. E. (Coord.). Visão 2030: O futuro da agricultura brasileira. Brasília, DF: Embrapa, 2018.

COSTABEBER, J. Acción Colectiva y Procesos de Transición Agroecológica en Rio Grande do Sul, Brasil. Tesis doctoral, Universidad de Córdoba - Espanha, 1998.

CAUME, D. J. C. A agricultura familiar no estado de Goiás. $2^{\text {a }}$ ed. Goiânia: Ed. da UFG, 2005.

FAO/INCRA- Organização das nações Unidas para a Agricultura/INCRA- Instituto Nacional de Colonização e Reforma Agrária. Diretrizes de Política Agrária e Desenvolvimento Sustentável. Brasília, Versão resumida do Relatório Final do Projeto UTF/BRA/036, março, 1994.

FAO/INCRA. Projeto de cooperação técnica INCRA/FAO. Novo retrato da agricultura familiar. O Brasil redescoberto. Brasília, 2000.

IBGE. Instituto Brasileiro de Geografia e Estatística. Censo agropecuário 2006. Disponível em: $<$ https://sidra.ibge.gov.br/pesquisa/censo-agropecuario/censoagropecuario-2006/segunda-apuracao >. Acesso em: 16 set. 2017.
IBGE. Instituto Brasileiro de Geografia e Estatística. Censo 2010 Goiás. Código do município. Disponível em: 〈https://censo2010.ibge.gov.br/sinopse/index.php?uf=52〉.

Acesso em: 16 set. 2017.

KNOREK. R. Agronegócio: um projeto como forma de alavancagem para o desenvolvimento da economia localregional voltado para a agricultura familiar da $26^{\mathrm{a}} \mathrm{SDR}$. Revista Cadernos de Economia, v. 15, n. 28, p. 49-58, 2011. 10.46699/rce.v15i28.1186.

MARIN, J. O. B. Agricultores familiares e os desafios da transição agroecológica. Revista UFG, v. 11, n. 7, p.38-45, 2009.

MARIN, J. O. B; MATOS, G. R. Agricultores familiares e sistemas de produção de frutas em Itapuranga, Goiás. Pesquisa Agropecuária Tropical, v.39, n. 3, p. 197-206, 2009.

MATOS, P. F.; PESSOA, V. L. S. A modernização da agricultura no Brasil e os novos usos do território. Geo Uerj, v. 2, n. 22, p. 290-322, 2011. 10.12957/geouerj.2011.2456.

MELETTI, L.M.M. Avanços na cultura do maracujá no Brasil. Revista Brasileira de Fruticultura. v.33, n. Especial, p. 83-91, 2011. 10.1590/S0100-29452011000500012.

NUNES DA SILVA, J.; MATTOS, J. S.; DINIZ, P. C. O.; VASCONCELOS, G. O. S. Transição agroecológica em assentamentos rurais: o processo inicial no assentamento Chico Mendes III/PE-Brasil. Revista Brasileira de Agroecologia, v. 4. n. 2, p. 3022-3025, 2009.

OLIVEIRA, D.; GRISA, C.; NIEDERLE, P. Inovações e novidades na construção de mercados para a agricultura familiar: os casos da Rede Ecovida de Agroecologia e da RedeCoop. Redes (St. Cruz Sul, Online), v. 25, n. 1, p. 135-163, 2020. 10.17058/redes.v25i1.14248.

PAULUS, G.; SCHLINDWEIN, S. L. Agricultura sustentável ou (re)construção do significado de agricultura? Agroecologia e desenvolvimento rural sustentável, v.2, n.3, p. 44-52, 2001.

PENTEADO, S. R. Implantação do cultivo orgânico: planejamento e plantio. [s.l.]: Do Autor, 2007.

RIBEIRO, D. D. FREITAS, L. F. de. Agroecologia: realidades e possibilidades produtivas. In: agroecologia práticas e saberes. organizador: Marcelo Rodrigues Mendonça. 2a ed. - Catalão: Modelo, 2012.

SCHNEIDER, S. Teoria Social, agricultura familiar e pluriatividade. Revista Brasileira de Ciências Sociais, v. 18, n. 51, p. 99-123, 2003. 10.1590/S0102-69092003000100008.

SCHNEIDER, S. Agricultura familiar e desenvolvimento rural endógeno: elementos teóricos e um estudo de caso. In: Froehlich, J.M.; Vivien Diesel. (Org.). Desenvolvimento Rural Tendências e debates contemporâneos. Ijuí: Unijuí, 2006.

VIEIRA, F. R. Valoração econômica de quintais rurais - o caso dos agricultores associados à COOPERAFI (Cooperativa de Agricultura Familiar de Itapuranga-Go). 2009. 118 f. Dissertação (Mestrado)- Universidade Federal de Goiás- UFG, Goiânia, 2009. 